\title{
Modelling, simulation and parameters estimation for gas networks
}

\author{
T. Rodríguez-Blanco*, D. Sarabia**, \\ C. de Prada* \\ * Dpt of Systems Engineering and Automatic Control, University of Valladolid, Doctor Mergelina s/n, 47011, Valladolid, \\ Spain(tania.rodriguez@autom.uva.es,prada@autom.uva.es). \\ ** Dpt of Electromechanical Engineering, University of Burgos, Avda. Cantabria s/n, 09006, Burgos, Spain \\ (dsarabia@ubu.es)
}

Keywords: Process simulators, estimation parameters, optimization problems, dynamic modelling, natural gas networks.

\section{INTRODUCTION}

This paper presents a library for the simulation of natural gas networks which contains dynamic components developed in the simulation environment EcosimPro. It comprises the main components of a natural gas network that have been modelled based on mass, energy and momentum balances and additional equations for describing the dynamic behaviour of real gases. The complete model that describes the natural gas transport has been adjusted to real data taken from a $127-\mathrm{km}$ long gas pipeline located in Mexico that is managed by the company Fermaca with a 16-inch pipe nominal diameter, one input, 4 outputs and an altitude difference of $397 \mathrm{~m}$. The results obtained show that the developed models can be used to accurately simulate real natural gas networks. A picture of the appearance of this library is shown in Fig.1:

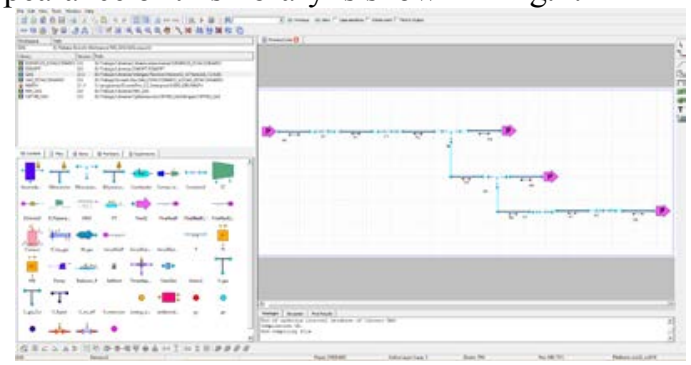

Fig.1. Dynamic library of natural gas networks in EcosimPro.

\section{THE FERMACA NETWORK}

Fermaca network is a $127-\mathrm{km}$ long gas pipeline with a 16 inch pipe nominal diameter and a total altitude difference of $397 \mathrm{~m}$. The receiver station is located in Palmillas and there are four supply points located in Atlacomulco, Pastejé, San Cayetano and Toluca. The topology is represented by Fig. 2 where the existing pressure (PT), temperature (TT), flow (FT) and composition (AT) sensors are represented.

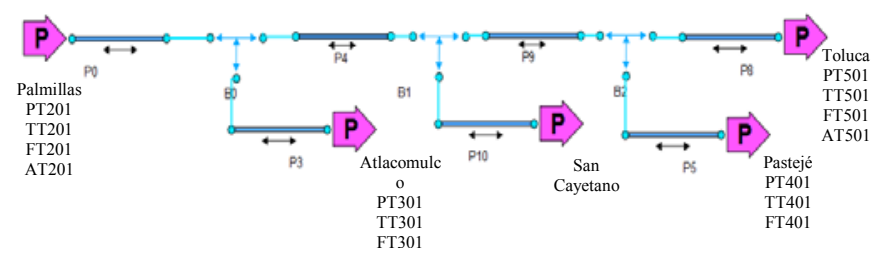

The dimensions of the gas pipelines are defined in Table 1.

Table 1. Dimensions of the gas pipelines

\begin{tabular}{|c|c|c|c|c|}
\hline Pipe & $\begin{array}{c}\text { Length } \\
(\mathrm{km})\end{array}$ & $\begin{array}{c}\text { Altitude } \\
\text { difference }(\mathrm{m})\end{array}$ & $\begin{array}{c}\text { Inlet } \\
\text { pressure } \\
\text { (bar) }\end{array}$ & $\begin{array}{c}\text { Outlet } \\
\text { pressure (bar) }\end{array}$ \\
\hline P0 & 64 & 308 & 51.55 & - \\
\hline P3 & 1 & 0 & - & 47.90 \\
\hline P4 & 12 & 4.5 & - & - \\
\hline P5 & 1 & 0 & - & 47.06 \\
\hline P8 & 39 & 80 & - & 45.53 \\
\hline P9 & 12 & 4.5 & - & - \\
\hline P10 & 1 & 0 & - & Estimated \\
\hline
\end{tabular}

The complete model comprises 3891 variables with 91 boundary conditions that evolve the inlet gas composition, one inlet and four outlet pressures, the inlet gas temperature and the environment temperature for each pipeline. The total number of equations is 3891 (2523 explicit and 1368 differential equations).

\section{PARAMETERS ESTIMATION}

Measurements from the inlet and outlet volumetric flow, temperature, concentration and pressure are available. These data have been adjusted by changing the pipeline efficiencies and the environment temperature. These measurements show that, for the chosen period of time, all the variables are in steady-state except the outlet temperatures in P3 and P5. This transient behaviour is because the outlet pipelines are not buried so the effect of the environment temperature on the gas temperature is bigger. The available measurements are graphically represented in Fig. 3, 4 and 5 that show the pressure profile, the temperature profile and the measured volumetric flow respectively.

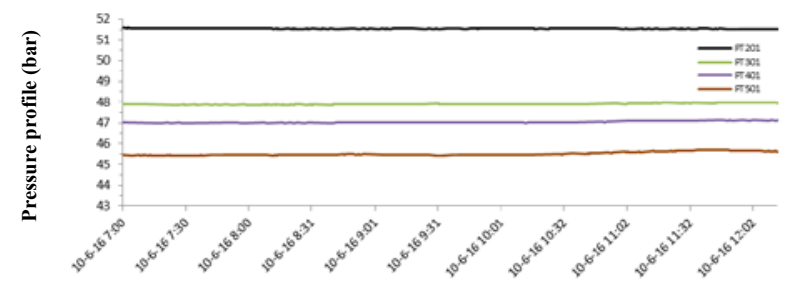

Fig. 3. Pressure profile.

Fig. 2. Fermaca network topology. 


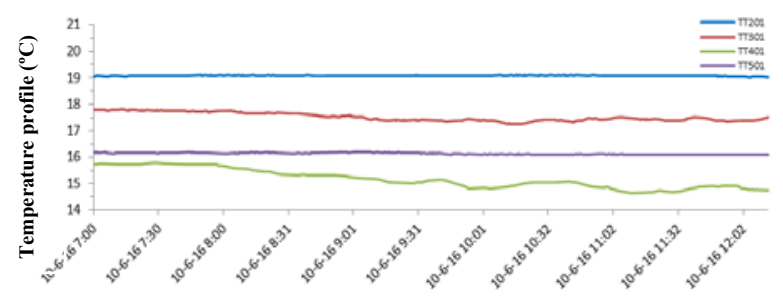

Fig. 4. Temperature profile.

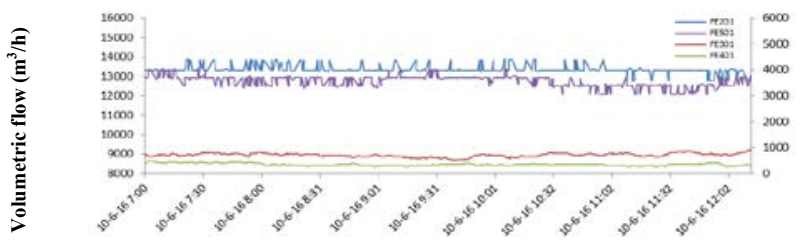

Fig. 5. Measured volumetric flow.

The data reconciliation problem to be solved is described by (1) where it can be observed that the cost function $J$ contains a stationary part to evaluate the differences between the real $\left(y_{\text {real }}\right)$ and the modelled variables $\left(y_{\text {mod }}\right)$ at the steady-state, and a dynamic component to evaluate the differences between the reality $\left(y_{d_{-} \text {real }}\right)$ and the model $\left(y_{d_{-} \text {mod }}\right)$ for the transient variables. For the dynamic reconciliation an environment temperature profile has been adjusted for P3 and P5 assuming that this profile follows a linear behaviour given by (2) where $t$ is the time expressed in hours:

$$
\begin{aligned}
& \min J=\left(y_{\text {real }}-y_{\text {mod }}\right)^{2}+\left(y_{d_{-} \text {real }}(t)-y_{d_{-} \text {mod }}(t)\right)^{2} \\
& u=\left[\begin{array}{lllllll}
e_{P 0} & e_{P 3} & e_{P 4} & e_{P 5} & e_{P 8} & e_{P 9} & e_{P 10}
\end{array}\right. \\
& \left.\begin{array}{llllll}
P_{\text {out } P 10} & a_{P 3} & b_{P 3} & a_{P 5} & b_{P 5} & T_{\text {envP8 }}
\end{array}\right] \\
& y_{\text {real }}=\left[\begin{array}{lllll}
Q_{\text {inP0 }} & Q_{\text {inP3 }} & Q_{\text {inP5 }} & Q_{\text {inP3 }} & T_{\text {outP8 }}
\end{array}\right] \\
& y_{d_{-} \text {real }}=\left[\begin{array}{ll}
T_{\text {out } P 3} & T_{\text {outP5 }}
\end{array}\right]
\end{aligned}
$$

$$
T_{\text {env }}=a \cdot t+b
$$

The NLP optimization problems have been solved using a sequential approach with a sequential quadratic programming (SQP) algorithm implemented in SNOPT library (Gill et al.,

\begin{tabular}{|c|c|c|}
\hline $\begin{array}{c}\text { Adjusted } \\
\text { parameter }(\mathrm{u})\end{array}$ & Description & Value \\
\hline$e_{P 0}(\#)$ & Efficiency of pipeline 0 & 1.106 \\
\hline$e_{P 3}(\#)$ & Efficiency of pipeline 3 & 0.122 \\
\hline$e_{P 4}(\#)$ & Efficiency of pipeline 4 & 1.131 \\
\hline$e_{P 5}(\#)$ & Efficiency of pipeline 5 & 0.101 \\
\hline$e_{P 8}(\#)$ & Efficiency of pipeline 8 & 1.069 \\
\hline$e_{P 9}(\#)$ & Efficiency of pipeline 9 & 1.11 \\
\hline$e_{P 10}(\#)$ & Efficiency of pipeline 10 & 0.108 \\
\hline$P_{\text {outP10 }}$ (bar) & Outlet pressure pipeline 10 & 47.418 \\
\hline$a_{P 3}\left({ }^{\circ} \mathrm{C} / \mathrm{h}\right)$ & Slope of $\mathrm{T}_{\mathrm{envP} 3}$ & -0.749 \\
\hline$b_{P 3}\left({ }^{\circ} \mathrm{C}\right)$ & Intercept of $\mathrm{T}_{\mathrm{env}} 3$ & 23.577 \\
\hline$a_{P 5}\left({ }^{\circ} \mathrm{C} / \mathrm{h}\right)$ & Slope of $\mathrm{T}_{\text {envP5 }}$ & -0.658 \\
\hline$b_{P 5}\left({ }^{\circ} \mathrm{C}\right)$ & Intercept of $\mathrm{T}_{\mathrm{env}} 5$ & 11.62 \\
\hline$T_{\text {envP } 8}\left({ }^{\circ} \mathrm{C}\right)$ & Environment temperature P8 & 16.00 \\
\hline
\end{tabular}
2008) and executed in EcosimPro software (EA Int, 2013).

The results obtained are shown in Table 3 which presents the value of the adjusted parameters and Table 4 where the stationary error is presented:

Table 3. Data reconciliation results
Table 4. Steady-state data reconciliation results

\begin{tabular}{|c|c|c|c|}
\hline Variable & yreal & ymod & Quadratic error \\
\hline$Q_{\text {in } P 0}\left(\mathrm{~m}^{3} / \mathrm{s}\right)$ & 3.713 & 3.715 & $4 \cdot 10^{-6}$ \\
\hline$Q_{\text {out } P 3}\left(\mathrm{~m}^{3} / \mathrm{s}\right)$ & 0.200 & 0.199 & $1 \cdot 10^{-6}$ \\
\hline$Q_{\text {out } P 5}\left(\mathrm{~m}^{3} / \mathrm{s}\right)$ & 0.097 & 0.097 & 0 \\
\hline$Q_{\text {out } P 8}\left(\mathrm{~m}^{3} / \mathrm{s}\right)$ & 3.510 & 3.494 & $2.5 \cdot 10^{-4}$ \\
\hline$T_{\text {out } P 8}\left({ }^{\circ} \mathrm{C}\right)$ & 16.17 & 16.178 & $6.4 \cdot 10^{-5}$ \\
\hline
\end{tabular}

The obtained results from the dynamic reconciliation are graphically shown in Fig. 6 where the measurements $\left(T_{\text {out } P 3}\right.$, $\left.T_{\text {outP5 }}\right)$ and the modelled $\left(T_{\bmod P 3}, T_{\operatorname{modP5}}\right)$ data are compared.

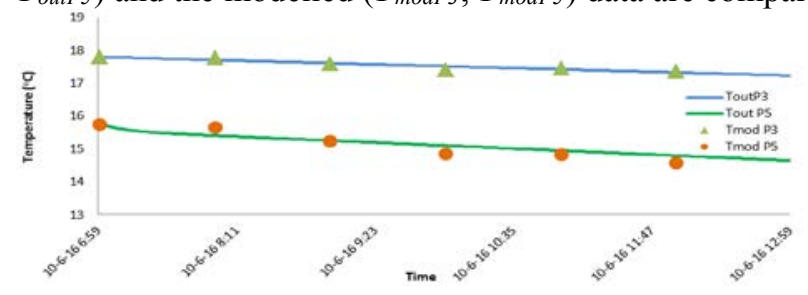

Fig. 6. Dynamic reconciliation result $\left(y_{d_{-} \text {real }}\right.$ and $\left.y_{d_{-} \text {mod }}\right)$, $T_{\text {outP3 }}$ and $T_{\text {outP5 }}$.

\section{CONCLUSIONS}

In this paper, a library for the simulation of natural gas networks has been presented. In addition, it has been demonstrate that this library can be used to simulate real networks after a previous step of data reconciliation.

Measurements taken from a real network has been used to adjust the model parameters such as: pipe efficiency or environment temperature. To make this, a data reconciliation problem is solved whose cost function combines a stationary part with a dynamic one. The results show that the model is adjusted perfectly to real data which allows using it for real simulations.

\section{ACKNOWLEDGMENTS}

The authors wish to express their gratitude to project DPI2015-70975-P of the Spanish MINECO/FEDER for the financial support for this study under FPI grant BES-2013062737. We would also like to thank Aplein Ingenieros and Intergeo Tecnología for their fruitful cooperation.

\section{REFERENCES}

Baliga, B. R., \& Patankar, S. V. (1983). A control volume finite-element method for two-dimensional fluid flow and heat transfer. Numerical Heat Transfer, 6(3), 245261.

EA Int, (2013). EcosimPro 5.2. User Manual (http://www.ecosimpro.com).

Gill, P. E., Murray, W., Saunders, M. A. (2008). User's Guide for SNOPT Version 7: Software for Large-Scale Nonlinear Programming.

Rodríguez, T., Sarabia, D. de Prada, C., Valbuena, M., Morales, J.L. (2013). Modelling and monitoring of natural gas networks. European Gas Technology Conference (EGATEC 2013).

Schroeder, D. W. (2001). A tutorial on pipe flow equations.

Woldeyohannes, A. D., \& Majid, M. A. A. (2011). Simulation model for natural gas transmission pipeline network system. Simulation Modelling Practice and Theory, 19(1), 196-212. 